\title{
Effect of Depth and Tubule Direction on Ultimate Tensile Strength of Human Coronal Dentin
}

\author{
Satoshi INOUE, Patricia N. R. PEREIRA ${ }^{1}$, Chiharu KAWAMOTO ${ }^{2}$, \\ Masatoshi NAKAJIMA ${ }^{3}$, Kenichi KOSHIRO ${ }^{2}$, Junji TAGAMI ${ }^{3}$, \\ Ricardo M. CARVALHO ${ }^{4}$, David H. PASHLEY ${ }^{5}$ and Hidehiko SANO ${ }^{2}$ \\ Section for General Dentistry, Hokkaido University \\ Dental Hospital, North 13 West 6, \\ Kita-ku, Sapporo 060-8586, Japan \\ ${ }^{1}$ Department of Operative Dentistry, School of Dentistry, \\ University of North Carolina at Chapel Hill, \\ Chapel Hill, NC, 27599-7450, USA \\ ${ }^{2}$ Department of Oral Health Science, Hokkaido University \\ Graduate School of Dental Medicine, North 13 West 7, \\ Kita-ku, Sapporo 060-8586, Japan \\ ${ }^{3}$ Department of Restorative Sciences, Graduate School, \\ Tokyo Medical and Dental University, 1-5-45, \\ Yushima, Bunkyou-ku, Tokyo, 113-8549, Japan \\ ${ }^{4}$ Department of Operative Dentistry, Endodontics and \\ Dental Materials, Bauru School of Dentistry, USP, \\ Bauru, SP, 17043-101, Brazil \\ ${ }^{5}$ Department of Oral Biology and Maxillofacial Pathology, \\ School of Dentistry, Medical College of Georgia, \\ Augusta, GA, 30912-1129, USA
}

Received September 26, 2002/Accepted December 25, 2002

\begin{abstract}
The purpose of this study was to evaluate the effect of dentin depth and tubule direction on the ultimate tensile strength (UTS) of human dentin. Dentin slabs of $0.5-\mathrm{mm}$ thickness were trimmed either from the mesial and distal (for specimens with the tubules parallel to the tensile force; parallel group) or from the occlusal and pulpal surfaces (perpendicular group) to reduce the cross-sectional area of the superficial, middle, and deep regions to $0.25 \mathrm{~mm}^{2}$, and subjected to microtensile testing. From SEM photomicrographs of the fractured specimens of the parallel group, the tubule density was investigated. For both parallel and perpendicular groups, superficial dentin showed a significantly higher UTS than deep dentin. The tubule density of superficial dentin was significantly lower than that of middle and deep dentin. When performing the microtensile bond test to deep dentin, it is possible that cohesive failure of dentin can occur at relatively low tensile stresses.
\end{abstract}

Key words: Ultimate tensile strength, Dentin depth, Dentinal tubule direction

\section{INTRODUCTION}

Bond strength measurements provide very important screening information of experimental or new products and on the effectiveness of bonding procedures or techniques. With the high bond strengths of current adhesive systems, it is often difficult to measure the true interfacial bond strength to dentin because a high percentage of 
cohesive fracture within dentin was observed when using a conventional testing method $^{1-3)}$. Stress concentration at the adhesive interface during testing often causes non-uniform stress distribution around the adhesive interface ${ }^{4-7)}$ that leads to cohesive failure of dentin at relatively low applied stresses.

The development of microtensile bond strength testing has helped to avoid such cohesive fractures within dentin ${ }^{8,9)}$. Microtensile testing is believed to create more uniform stress distribution and to result in fewer cohesive fractures of dentin during resin-dentin bond testing. Moreover, it is very useful as a material screening test ${ }^{10-12)}$, testing resin bonds to abnormal dentin ${ }^{13,14)}$, and evaluating the bond strength when resins are placed in clinically relevant $3-\mathrm{D}$ cavity wall ${ }^{15,16)}$. This testing methodology also makes it possible to evaluate the long-term durability of dentin bonding in vivo $^{17-19)}$ and in vitro ${ }^{20,21)}$. Thus, the utility of the microtensile test was recognized and the testing method has spread world-wide.

Recent improvements in new bonding systems have resulted in higher bond strength than previous versions. In the last decade, the microtensile bond test should have reduced the incidence of cohesive failure in dentin with these high bond strengths, compared with conventional testing methods. Sano et al. ${ }^{8,22}$ measured the ultimate tensile strength (UTS) of human coronal dentin, and found that it was significantly greater than resin-dentin bond strengths obtained using the microtensile bond testing (i.e., dentin UTS of more than $100 \mathrm{MPa}$ vs. resin-dentin bond strengths ranged from 30 to $60 \mathrm{MPa}$ ). However, some recent studies reported cohesive failures in dentin using the microtensile bond testing ${ }^{12,15,17,23,24)}$, but few studies specified the depth of dentin or the direction of dentinal tubules relative to the direction of loading.

Smith and Cooper ${ }^{25)}$, using a micro-punch method, reported the shear strengths of dentin ranged from $39 \mathrm{MPa}$ (near the pulp) to $131 \mathrm{MPa}$ (near the dentino-enamel junction). Watanabe et al. ${ }^{26)}$ reported the anisotropy of the dentin shear strength regarding the tubule orientation and site of dentin tested. However, the use of the shear test to evaluate bond strength and mechanical properties has been criticized because of the non-uniform stress distribution and $\mathrm{flow}^{6,9)}$. Testing in tension, with small surface areas, has become more popular as researchers could measure resindentin bond strengths with greater reliability ${ }^{3,7)}$. Recent studies also demonstrated the anisotropy of the tensile strength of dentin ${ }^{27-31)}$ using bovine or human dentin. Moreover, Kinney et $a l .{ }^{32)}$ demonstrated that the hardness and modulus of the intertubular dentin were lower in the inner dentin than in the outer dentin.

Since dentin is not a uniform substrate, bonding to dentin with low regional cohesive strength might cause cohesive failures within dentin during tensile bond testing. Therefore, it is of significant importance to test the ultimate tensile strength of dentin from different sites of dentin. The purpose of the present study was to evaluate the effect of dentin depth and the direction of tubules on the ultimate strength of dentin tested in tension. 


\section{MATERIALS AND METHODS}

\section{Teeth}

Thirty-six noncarious human third molars were used for this study. After extraction, the teeth were stored in distilled water with a few crystals of thymol for 1-4 weeks at $4^{\circ} \mathrm{C}$.

\section{Tensile Test}

Two to three dentin slabs, each approximately $0.5-\mathrm{mm}$ thick, were sectioned from each tooth mesio-distally in a direction parallel to the long axis of the tooth by means of a low speed diamond saw (Isomet, Buehler, Lake Bluff, IL, USA) under copious water irrigation. Each slab was gently trimmed either from the mesial and distal, or from the occlusal and pulpal surfaces, using a super-fine diamond bur under water spray coolant. This was done to reduce the various regions (i.e., superficial, middle, and deep) of the coronal dentin to a cross-sectional area of approximately $0.25 \mathrm{~mm}^{2}$ (mean thickness and breadth of the narrowest portion of the slabs were $0.51 \pm 0.05 \mathrm{~mm}$ and $0.50 \pm 0.04 \mathrm{~mm}$, respectively) as reported previously ${ }^{8,33)}$. Radius of the narrowest portion was $0.63 \mathrm{~mm}$. The slabs trimmed from the mesial and distal aspects were used to test the strength of dentin with tubules oriented parallel to the applied force (parallel group) (Fig. 1). The slabs trimmed from the occlusal and pulpal surfaces were used to test the strength of dentin with tubules oriented

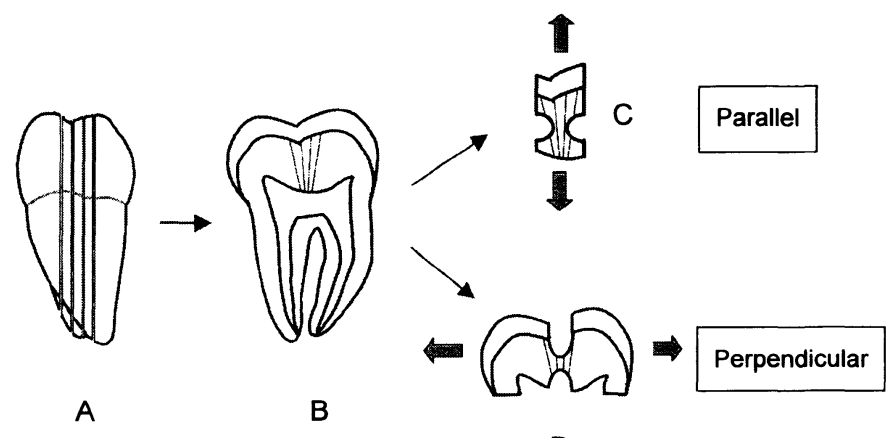

D

Fig. 1 Schematic drawing of specimen preparation procedures for ultimate tensile strength.

Extracted human tooth was sectioned parallel to the long axis of the tooth (A) and two or three dentin slabs of $0.5-\mathrm{mm}$ thickness were obtained (B). Each slab was gently trimmed either from the mesial and distal (C) or from the occlusal and pulpal surfaces (D). The slabs trimmed from the mesial and distal aspects were used as specimens to test the strength of dentin with the tubules parallel to the applied force. The slabs trimmed from the occlusal and pulpal surfaces were used to test the strength of dentin with the tubules perpendicular to the applied force. 
perpendicular to the applied force (perpendicular group) (Fig. 1).

To determine how far from the dentino-enamel junction each trimmed specimen was, the final position called the percentage dentin depth of the specimens was given by the following equation:

Percentage Dentin Depth $(\mathrm{PDD})=(\mathrm{TDH}-\mathrm{RDT}) / \mathrm{TDH} \times 100$, where TDH is the total dentin thickness measured from dentino-enamel junction to pulpal wall and RDT is the distance between the narrowest portion of the specimen and pulpal wall.

Trimmed specimens were divided into three different subgroups with regard to the percentage dentin depth; Superficial $(0<\mathrm{PDD}<33.3)$, Middle $(33.3<\mathrm{PDD}<66.6)$, and Deep $(66.6<\mathrm{PDD}<100)$. The specimens were glued to Ciucchi's jig $^{9)}$ with cyanoacrylate adhesive (Model Repair II Blue, Sankin Co., Otahara, Japan), and mounted in a microtensile testing apparatus. Testing was performed under tension using a desk-top testing machine (EZ-Test, Shimadzu Co., Kyoto, Japan) at a crosshead speed of $1 \mathrm{~mm} / \mathrm{min}$. The ultimate tensile strength (UTS) was calculated by dividing the maximum load at failure $(\mathrm{N})$ by the cross-sectional area $\left(\mathrm{mm}^{2}\right)$ and expressed in $\mathrm{MPa}$.

\section{Calculation of the Tubule Density}

When the specimens were pulled to failure in tension to determine the UTS values, the fractured surfaces were very clean. The fractured specimens of the parallel group were mounted on the aluminum stubs, and then dried in a desiccator for 48 hours, gold-sputtered, and examined using a field emission scanning electron microscope (FE-SEM) (S-4000, Hitachi, Tokyo, Japan). Representative photomicrographs were taken from the fractured specimens at $\times 2,000$ magnification. The number of dentinal tubules was counted on the photomicrographs in an area of $500 \mu \mathrm{m}^{2}$ in the center portion of the fractured specimens, and the density of tubules was expressed as the number of tubules per $\mathrm{mm}^{2}$ for each specimen.

\section{Statistics}

The UTS data were analyzed using a two-way ANOVA test. Independent variables were dentin depth (PDD) and tubule direction. Intra-group comparisons were performed using one-way ANOVA and Fisher's PLSD test at a confidence level of $\alpha$ $=0.05$. Linear regression analysis between PDD and the UTS for both applied force directions was performed. For the comparison of the tubule density of each group, one-way ANOVA and Fisher's PLSD test at a confidence level of $\alpha=0.05$ was performed.

\section{RESULTS}

The results of the ultimate tensile strength testing are shown in Table 1. Two-way ANOVA revealed significant differences in UTS as a function of the direction of the applied load $(p=0.0014)$ and of dentin depth $(p=0.0022)$. There was no significant 
Table 1 Ultimate tensile strength of dentin as a function of direction of tensile load and dentin depth

\begin{tabular}{lccc}
\hline Direction of load & Superficial & Middle & Deep \\
\hline Parallel & $77.6 \pm 24.7(10)^{\mathrm{a}}$ & $65.2 \pm 21.2(10)$ & $50.9 \pm 15.4(10)^{\mathrm{a}}$ \\
& & & \\
Perpendicular & $99.8 \pm 27.9(11)^{\mathrm{b}}$ & $94.5 \pm 30.7(12)^{\mathrm{c}}$ & $65.0 \pm 32.5(11)^{\mathrm{b}, \mathrm{c}}$ \\
\hline
\end{tabular}

Values are shown as means \pm SD (number of specimens) in MPa. Values designated with the same superscript letter are significantly different $(p<0.05)$.

Table 2 Tubule density (number of dentinal tubules $/ \mathrm{mm}^{2}$ ) of fractured dentin surface of specimens pulled in parallel direction

\begin{tabular}{ll}
\hline \multicolumn{1}{c}{ Dentin depth } & \multicolumn{1}{c}{ Tubule density } \\
\hline Superficial & $2.13 \times 10^{4}\left(9.94 \times 10^{3}\right)^{\mathrm{a}, \mathrm{b}}$ \\
Middle & $3.29 \times 10^{4}\left(1.17 \times 10^{4}\right)^{\mathrm{a}}$ \\
Deep & $3.78 \times 10^{4}\left(6.26 \times 10^{3}\right)^{\mathrm{b}}$ \\
\hline
\end{tabular}

Values are shown as means (SD). Values designated with the same superscript letter are significantly different ( $p$ $<0.05$ ). Measurements were performed in the center portion of the fractured specimen surface.

interaction $(p=0.7246)$ between these two factors. Overall comparison for the direction of applied load demonstrated that the UTS of specimens stressed perpendicular to the tubule direction was significantly greater than that of specimens stressed parallel to the tubule orientation $(p=0.0009)$. For the overall comparison of dentin depth, the UTS of deep dentin was significantly lower than that of superficial dentin $(p=0.0005)$ and middle dentin $(p=0.0086)$, whereas no significant difference in UTS was found between superficial and middle dentin $(p=0.3234)$.

Intra-group comparisons are also listed in Table 1. For the parallel group, the UTS of superficial dentin $(77.6 \pm 24.7 \mathrm{MPa})$ was significantly higher than that of deep dentin $(50.9 \pm 15.4 \mathrm{MPa})$. The UTS of middle dentin $(65.2 \pm 21.2 \mathrm{MPa})$ from the parallel group failed to show a significant difference for both superficial and deep dentin. For the perpendicular group, the UTS of superficial dentin $(99.8 \pm 27.9 \mathrm{MPa})$ was significantly higher than that of deep dentin $(65.0 \pm 32.5 \mathrm{MPa})$. The middle dentin from the perpendicular group $(94.5 \pm 30.7 \mathrm{MPa})$ also showed significantly higher UTS than deep dentin. There was no significant difference in UTS found between superficial and middle dentin from the perpendicular group.

The linear regression analysis of UTS vs. PDD for the perpendicular group showed a significant linear relation $\left(p<0.0001, \mathrm{R}^{2}=0.821\right.$, UTS $\left.=1.602 \times \mathrm{PDD}\right)$. A similar highly significant linear relation was also found for the parallel group ( $p$ $<0.0001, \mathrm{R}^{2}=0.836$, UTS $\left.=1.059 \times \mathrm{PDD}\right)$.

Table 2 demonstrated the tubule density of the different depths of dentin from the parallel group. The tubule density of superficial dentin $\left(2.13 \times 10^{4} \pm 9.94 \times 10^{3}\right)$ was 
significantly lower than that of middle $\left(3.29 \times 10^{4} \pm 1.17 \times 10^{4}\right)$ and deep dentin (3.78 $\left.\times 10^{4} \pm 6.26 \times 10^{3}\right)$. There were no significant differences in tubule density between middle and deep dentin.

\section{DISCUSSION}

The results of this study demonstrated that the UTS of deep dentin was lower than superficial and middle dentin, in agreement with measurements of the micro-punch shear test ${ }^{25)}$, shear streng $\operatorname{th}^{26)}$ and tensile $\operatorname{streng} \mathrm{th}^{31)}$. Although no significant correlation between the UTS and tubule density was found in the present study, there was a tendency for increased numbers of tubules per $\mathrm{mm}^{2}$ to produce lower UTS (Table 2). The tubule density increased as PDD increased. Increased tubule density in deep dentin is one of the reasons for the weak mechanical property of deep dentin. It is reasonable to assume that the higher the tubules density, the lower the amount of solid dentin to provide mechanical strength. Carvalho et $a l^{27)}$ reported similar findings. They made a comparison between the UTS and density of tubules and suggested a possible correlation between the UTS and tubule density. Although the amount of solid dentin is affected by both the tubule density and the diameter of dentinal tubules, the latter was not evaluated in the present study. The diameter of dentinal tubules is in general thought to be diverse depending on the dentin region. In other words, the deeper the dentin depth, the wider the diameter. Further research should be performed in detail on the diameter of the dentinal tubules on the fractured dentin surface.

Anisotropy of tensile strength of coronal dentin was also confirmed in the present study. Watanabe et $a l^{26)}$ reported anisotropy of shear strength of human coronal dentin regarding tubule orientation. Lertchirakarn et al. ${ }^{28)}$ demonstrated anisotropy of tensile strength of human root dentin, showing the UTS was lowest when the tensile force was parallel to the tubule direction, and greatest at $90^{\circ}$ to tubule orientation. Similar findings were reported using bovine dentin ${ }^{29,30}$ and human coronal dentin ${ }^{27,31)}$. Currently, the anisotropic behavior of dentin is of great interest.

To explain the anisotropy of the cohesive strength of dentin, Inoue et al. ${ }^{29)}$ presented an interesting model using bovine dentin. They compared the cross-sectioned area of solid dentin in $1 \mathrm{~mm}^{2}$ specimens taken from specimens pulled in tension perpendicular versus parallel to the tubule orientation. This area was $0.89 \mathrm{~mm}^{2}$ for the perpendicular tubule orientation and 0.65 to $1 \mathrm{~mm}^{2}$ for the parallel orientation. This discrepancy of the cross-sectional area may be responsible for the higher UTS when dentin is pulled perpendicular to the tubule direction. Moreover, they suggested that the cross-sectioned dentinal tubules could be considered as potential pre-cracks or voids, that were different depending on the direction of stresses. When the specimens are stressed perpendicular to the tubule direction, the ideal cross-sectional shape of tubules is rectangular whereas the shape of tubules stressed in a parallel direction is round. Their fractographic analysis suggested that half of the origin of the cracks stressed parallel to tubule orientation were located at the periphery or edge of the 
specimen. On the other hand, half of the estimated fracture origin was located inside of the specimen pulled perpendicular to tubule orientation. Although we failed to find the fracture origins after testing, fractographical analysis could lead to a better understanding of the anisotropy of dentin.

Several studies have suggested that the orientation of collagen fibrils in composite materials such as bone and dentin influences strength ${ }^{34,35)}$. Collagen fibrils are interwoven and arranged perpendicular to tubules ${ }^{36)}$, and apatite crystals tend to be positioned parallel with the long axis of collagen fibrils. Thus, fractures caused by force application parallel to tubule direction occur predominantly within the plane of the collagen network, while fractures produced by the loads applied perpendicular to the tubule direction require disruption of the collagen fibrils. Collagen fibril orientation should be considered in any explanation for the anisotropy of the tensile strength of coronal dentin.

According to the result of this study, dentin tensile strength was anisotropic and deep dentin showed very low UTS (i.e. 50-60 MPa) values. Linear regression analysis between the UTS and percent dentin depth in the present study also clearly demonstrated that dentin strength became reduced as the dentin depth increased. The microtensile test has enabled evaluation of regional dentin strength. The specimen dimensions employed in this study gave a cross-sectional surface area of approximately $0.25 \mathrm{~mm}^{2}$. This size is a quarter of the size of the $1 \mathrm{~mm}^{2}$ that has been most commonly used for the microtensile bond strength test. When the UTS is measured on specimens with a cross-sectional area of $0.5 \mathrm{~mm}^{2}$, the values were lower (57.6士 11.0 $\mathrm{MPa}$ parallel to tubules and $80.0 \pm 13.6 \mathrm{MPa}$ perpendicular to the tubule orientation ${ }^{27)}$. When $1 \mathrm{~mm}^{2}$ dentin specimens were tested, the UTS was only $18.3 \pm 6.5 \mathrm{MPa}$ when the specimens were tested perpendicular to the direction of the tubules. Thus, the cohesive strength of dentin is dependent on cross-sectional area, suggesting that contains flaws ${ }^{37)}$. These observations suggest that it is crucial that investigators state the precise specimen size, especially the cross-sectional area, when reporting dentin strength measurements. Moreover, when performing the microtensile bond test to deep dentin, there is a possibility that cohesive failures occur at relatively low stress values, as indicated by the results of the present study. The proper interpretation of such results requires the mode of failure in dentin to be reported in any microtensile bond test.

\section{ACKNOWLEDGEMENTS}

This work was supported in part by a Grant-in-Aid for Scientific Research from the Japan Society for Promotion of Science \#11470401.

\section{REFERENCES}

1) Perinka, L., Sano, H. and Hosoda, H.: Dentin thickness, hardness, and Ca-concentration vs. bond strength of dentin adhesives, Dent Mater 8:229-233, 1992.

2) Burrow, M.F., Tagami, J. and Hosoda, H.: The long term durability of bond strengths 
to dentin, Bull Tokyo Med Dent Univ 40 : 173-191, 1993.

3) Pashley, D. H., Sano, H., Ciucchi, B., Yoshiyama, M. and Carvalho, R. M.: Adhesion testing of dentin bonding agents: A review, Dent Mater $11: 117-125,1995$.

4) Van Noort, R., Noroozi, S., Howard, I. C. and Cardew, G. E.: A critique of bond strength measurements, J Dent $17: 61-67,1989$.

5) Van Noort, R., Cardew, G. E, Howard, I. C. and Noroozi, S.: The effect of local interfacial geometry on the measurement of the tensile bond strength to dentin, J Dent Res $70: 889-893,1991$.

6) Della Bona, A. and Van Noort, R.: Shear vs. tensile bond strength of resin composite bonded to ceramic, $J$ Dent Res $74: 1591-1596,1995$.

7) Van Noort, R.: Dentine bonding. Bond strength measurements. In: Lloyde CH, Scimgeor N (eds). Dental Materials: 1995 literature review, J Dent 25 : 178-179, 1997.

8) Sano, H., Ciucchi, B., Matthews, W. G. and Pashley, D. H.: Tensile properties of mineralized and demineralized human and bovine dentin, $J$ Dent Res 73 : 1205-1211, 1994.

9) Pashley, D. H., Carvalho, R. M., Sano, H., Nakajima, M., Yoshiyama, M., Shono, Y., Fernandes, C. A. and Tay, F. R.: The micro-tensile bond test: A review, $J$ Adhesive Dent $1: 299-309,1999$.

10) Inoue, S., Vargas, M. A., Van Meerbeek, B., Abe, Y., Yoshida, Y., Lambrechts, P., Vanherle, G. and Sano, H.: Micro-tensile bond strength of eleven modern adhesives to dentin. $J$ Adhesive Dent $3:$ 237-245, 2001.

11) Inoue, S., Vargas, M. A., Van Meerbeek, B., Abe, Y., Yoshida, Y., Lambrechts, P., Vanherle, G. and Siano, H.: Micro-tensile bond strength of eleven modern adhesives to enamel. Am J Dent 15, 2002 (in press).

12) De Munck, J., Van Meerbeek, B., Inoue, S., Vargas, M., Yoshida, Y., Armstrong, S., Lambrechts, P. and Vanherle, G.: Micro-tensile bond strengths of one- and two-step selfetch adhesives to bur-cut enamel and dentin, Am J Dent 15, 2002 (in press).

13) Nakajima, M., Sano, H., Burrow, M. F., Tagami, J., Yoshiyama, M., Ebisu, S., Ciucchi, B., Russell, C. M. and Pashley, D. H.: Tensile bond strength and SEM evaluation of caries-affected dentin using dentin adhesives. J Dent Res 74:1679-1688, 1996.

14) Yoshiyama, M., Sano, H., Ebisu, S., Tagami, J., Ciucchi, B., Carvalho, R. M., Johnson, M. H. and Pashley, D. H.: Regional strengths of bonding agents to cervical sclerotic root dentin. J Dent Res 75 : 1404-1413, 1996.

15) Yoshikawa, T., Sano, H., Burrow, M. F., Tagami, J. and Pashley, D. H.: Effects of dentin depth and cavity configuration on bond strength, $J$ Dent Res $78: 898-905,1999$.

16) Bouillague, S., Ciucchi, B., Jacoby, T., Wataha, J. C. and Pashley, D. H.: Bonding characteristics to dentin walls of class II cavities, in vitro, Dent Mater 17:316-321, 2001.

17) Sano, H., Pereira, P. N. R., Yoshikawa, T., Morigami, M., Tagami, J. and Pashley, D. H.: Long-term durability of dentin bonds made with a self-etching primer, in vivo, $J$ Dent Res 78 : 906-911, 1999.

18) Hashimoto, M., Ohno, H., Kaga, M., Endo, K., Sano, H. and Oguchi, H.: In vivo degradation of resin-dentin bonds in humans over 1 to 3 years, $J$ Dent Res 79:1385-1391, 2000.

19) Takahashi, A., Inoue S., Kawamoto, C., Ominato, R., Tanaka, T., Sato, Y., Pereira, P. N. R. and Sano, H.: In vivo long-term durability of the bond to dentin using two adhesive systems, $J$ Adhesive Dent $4: 2002$ (in press).

20) Hashimoto, M., Ohno, H., Sano, H., Tay, F. R., Kaga, M., Kudou, Y., Oguchi, H., Araki, Y. and Kubota, M.: Micromorphological changes in resin-dentin bonds after oneyear water storage, $J$ Biomed Mater Res $63: 306-311,2002$

21) Van Meerbeek, B., De Munck, J., Yoshida, Y., Inoue, S., Vargas, M., Lambrechts, P. and Vanherle G.: Micro-tensile bond strength of 4 total-etch adhesives to dentin after 4year water storage, J Dent Res 81(Special Issue A), A-138, 2002.

22) Sano, H., Shono, T., Sonoda, H., Takatsu, T., Ciucchi, B., Carvalho, R. M. and Pashley, D. H.: Relationship between surface area for adhesion and tensile bond strength - Evaluation of a micro tensile bond test, Dent Mater $10: 236-240,1994$. 
23) Armstrong, S. R., Boyer, D. B. and Keller, J. C.: Microtensile bond strength testing and failure analysis of two dentin adhesives, Dent Mater 14:44-50, 1998.

24) Pereira, P. N. R., Okuda, M., Sano, H., Yoshikawa, T., Burrow, M. F. and Tagami, J.: Effect of intrinsic wetness and regional difference on dentin bond strength, Dent Mater $15: 46-53,1999$.

25) Smith, D.C. and Cooper, W. E.: The determination of shear strength. A method using a micro-punch apparatus, $B r$ Dent $J 130$ : 333-337, 1971.

26) Wantanabe, L. G., Marshall, G. W. and Marshall, S. J.: Dentin shear strength: Effects of tubule orientation and intratooth location, Dent Mater 12:109-115, 1996.

27) Carvalho, R. M., Fernandes, C. A. O., Villanueva, R., Wang, L. and Pashley, D. H.: Tensile strength of human dentin as a function of tubule orientation and density, $J$ Adhesive Dent $3:$ 309-314, 2001.

28) Lertchirakarn, V., Palamara, J.E. A. and Messer, H. H.: Anisotropy of tensile strength of root dentin, $J$ Dent Res $80: 453-456,2001$.

29) Inoue, T., Takahashi, H. and Nishimura, F.: Anisotropy of tensile strength of bovine dentin regarding dentinal tubule orientation and location, Dent Mater $J$ 21:32-43, 2002.

30) Liu, J., Hattori, M., Hasegawa, K., Yoshinari, M., Kawada, E. and Oda, Y.: Effect of tubule orientation and location on the microtensile strength of bovine root dentin, Dent Mater $J 21$ : 73-82, 2002.

31) Staninec, M., Marshall, G. W., Hilton, J.F., Pashley, D. H., Gansky, S. A., Marshall, S. J. and Kinney, J. H.: Ultimate tensile strength of dentin: Evidence for a damage mechanics approach to dentin failure, $J$ Biomed Mater Res 63:342-345, 2002.

32) Kinney, J. H., Balooch, M., Marshall, S. J., Marshall, G. W. and Weihs, T. M.: Hardness and Young's modulus of peritubular and intertubular dentine, Archs Oral Biol 41:9-13, 1996.

33) Sano, H., Takatsu, T., Ciucchi, B., Russell, C. M. and Pashley, D. H.: Tensile properties of resin-infiltrated demineralized human dentin, $J$ Dent Res 74:1093-1102, 1995.

34) Rasmussen, S. T. and Patchin, R. E.: Fracture properties of human enamel and dentin in an aqueous environment, $J$ Dent Res $63: 1362-1368,1984$.

35) Currey, J. D., Brear, K. and Zioupos, P.: Dependence of mechanical properties on fibre angel in narwhal tusk, a highly oriented biological composite, $J$ Biomech 27 :885-897, 1994.

36) Sogarrd-Pedersen, B., Boye, H. and Matthiessen, M. E.: Scanning electron microscope observations on collagen fibrils in human dentin and pulp, Scand J Dent Res 98:89-95, 1990.

37) Pashley, D. H., Agee, K. A., Carvalho, R. M., Lee, K-W., Tay, F. R. and Callison, T. E.: Effect of water-free polar solvents on the tensile properties of demineralized dentin, Dent Mater 19, 2003 (in press). 